Marina Peñuelas ${ }^{1}$

Cristina Garcia-Salguero'

Melania Iñigo ${ }^{2}$

Jose Manuel Viñuela-Prieto ${ }^{3}$

Francisco Javier Candel ${ }^{4}$

José Luis del Pozo ${ }^{5}$

Esther Culebras ${ }^{1}$

\section{In vitro activity of imipenem/relebactam against Gram-negative clinical isolates in two Spanish tertiary hospitals}

\author{
'Department of Clinical Microbiology, Hospital Clínico San Carlos, IdISCC and IML Health Research Institutes, \\ Complutense University, Madrid, Spain \\ 2Department of Clinical Microbiology, Clinica Universitaria de Navarra, Campus Madrid, Spain \\ ${ }^{3}$ School of Medicine, Complutense University, Madrid, Spain \\ ${ }^{4}$ Clinical Microbiology and Infectious Diseases, Hospital Clinico San Carlos, IdISCC and IML Health Research Institutes, \\ Complutense University, Madrid, Spain \\ ${ }^{5}$ Clinical Microbiology and Infectious Diseases, Clinica Universitaria de Navarra, Campus Pamplona, Spain
}

Article history

Received: 15 August 2021; Accepted: 12 September 2021; Published: 13 October 2021

\begin{abstract}
Objetive. The aim of this study was to analyze the activity of the imipenem-relebactam combination (IMI/REL) against a collection of multidrug-resist Enterobacterales, Pseudomonas aeruginosa and Acinetobacter baumannii clinical isolates.

Material and methods. The study was conducted in two tertiary hospitals in Spain and included 192 clinical isolates of these 3 genera (139 resistant and 53 susceptible to IMI). The MICs for IMI with and without REL (at a fixed concentration of $4 \mathrm{mg} / \mathrm{L}$ ) were determined by a standard broth microdilution method according to international recommendations.
\end{abstract}

Results. All IMI-susceptible E. coli strains were also susceptible to IMI/REL. Enterobacterales resistant to IMI due to the production of carbapenemases, the $\mathrm{MIC}_{50}$ and $\mathrm{MIC}_{90}$ decreased from 64/256 with IMI to 8/64 mg/L with IMI/REL. This high activity was principally detected among isolates with KPC enzymes. Enterobacterales with class B carbapenemases, $P$. aeruginosa carrying $\mathrm{VIM}$ carbapenemase and $A$. baumannii strains showed no changes on IMI $\mathrm{MIC}_{50}$ or $\mathrm{MIC}_{90}$ after adding REL. Among $P$. aeruginosa strains without carbapenemase the MIC for IMI/REL was reduced between 1 to 5 dilutions.

Conclusions. IMI/REL showed high activity against the strains that carry Klebsiella pneumoniae carbapenemase (KPC) and against carbapenem-resistant $P$. aeruginosa unrelated to the VIM enzyme, mainly AmpC beta lactamase associated with impermeability. Against strains carrying oxacillinase 48 (OXA48) associated with extended-spectrum beta-lactamase (ESBL), IMI/REL presented activity only slightly better than IMI and had no beneficial effect superior to IMI against $A$. baumannii.

Keywords: Imipenem-relebactam, Pseudomonas aeruginosa, Carbapenemresistant Enterobacterales, Klebsiella pneumoniae carbapenemase, oxacillinase 48, Extended-spectrum beta-lactamase.

Correspondence:

Francisco Javier Candel González. MD PhD.

Clinical Microbiology and Infectious Diseases. IdISCC and IML Health Research Institutes.

Hospital Clinic San Carlos. Madrid, Spain

Email: franciscojavier.candel@salud.madrid.org
Actividad in vitro de imipenem/relebactam frente aislados clínicos de gramnegativos en dos hospitales terciarios españoles

\section{RESUMEN}

Objetivo. El objetivo de este estudio fue analizar la actividad de la combinación imipenem-relebactam (IMI/REL) frente a una colección de aislados clínicos multirresistentes de Enterobacterales, Pseudomonas aeruginosa y Acinetobacter baumannii.

Material y métodos. El estudio se realizó en dos hospitales terciarios de España e incluyó 192 aislados clínicos de estos 3 géneros (139 resistentes y 53 susceptibles a IMI). Las CMI para IMI con y sin REL (a una concentración fija de $4 \mathrm{mg} / \mathrm{L}$ ) se determinaron por un método estándar de microdilución en caldo según las recomendaciones internacionales.

Resultados. Todas las cepas de E. coli sensibles a IMI fueron también sensibles a IMI/REL. En el caso de las enterobacterias resistentes a $\mathrm{IMI}$ debido a la producción de carbapenemasas, la $\mathrm{CMI}_{50}$ y la $\mathrm{CMI}_{90}$ disminuyeron de 64/256 con IMI a 8/64 con IMI/REL. Esta elevada actividad se detectó principalmente entre los aislados con enzimas KPC. Las enterobacterias con carbapenemasas de clase $B, P$. aeruginosa portadora de carbapenemasas VIM y las cepas de $A$. baumannii no mostraron cambios en la $\mathrm{CMI}_{50}$ ni en la $\mathrm{CMI}_{90}$ tras añadir REL. Entre las cepas de $P$ aeruginosa sin carbapenemasas, la CMI para IMI/ REL se redujo entre 1 y 5 diluciones.

Conclusiones. IMI/REL mostró una elevada actividad frente a las) y frente a Pseudomonas aeruginosa resistente a carbapenemasas no relacionadas con la enzima VIM, principalmente AmpC beta lactamasa asociada a la impermeabilidad. Contra las cepas portadoras de oxacilinasa 48 (OXA-48) asociadas a betalactamasas de espectro extendido (ESBL), IMI/ cepas portadoras de Klebsiella pneumoniae carbapenemasa (KPC). REL presentó una actividad sólo ligeramente mejor que 
IMI y no tuvo un efecto beneficioso superior a IMI contra $A$. baumannii.

Palabras clave: Imipenem, Imipenem-relebactam, Pseudomonas aeruginosa, Enterobacteriaceae resistentes a los carbapenémicos, beta-lactamasa de espectro extendido.

\section{INTRODUCTION}

The continuing emergence of antibiotic resistance in the community and hospitals is considered a major public health threat $[1,2]$. This resistance is mainly due to the presence of carbapenemase enzymes and the addition of other resistance mechanisms frequently related with the external membrane's permeability [1].

To avoid this problem, various combinations of beta-lactam antibiotics and beta-lactamase inhibitors have been developed. Relebactam (REL) is a new inhibitor of class $A, C$ and certain D beta-lactamases (not active against OXA-48 beta-lactamase), which in combination with imipenem (IMI) has recently been approved by the European Medicines Agency (EMA) and the Food and Drug Administration (US FDA). IMI/ REL combination can restore carbapenem's activity when resistance is due class A or certain type D carbapenemases, either alone or in combination with other resistance mechanisms, mainly extended-spectrum beta-lactamases (ESBL) and AmpC beta-lactamases $[3,4]$.

The aim of this study was to evaluate the in vitro activity of IMI/REL against 192 clinical isolates (139 resistant and 53 susceptible to imipenem) from the collections of the Department of Microbiology of Hospital Clínico San Carlos de Madrid and Clínica Universitaria de Navarra.

\section{MATERIAL AND METHODS}

Strains were selected according to their resistance mechanisms including the most common of them. Table 1 shows the distribution of these isolates according to their predominant resistance mechanism. The resistance genes were either previously characterized $[5,6]$ or detected using polymerase chain reaction with specific primers. Isolates were subcultivated at least twice in Mueller-Hinton agar before proceeding to minimum inhibitory concentration (MIC) determination. IMI and REL were supplied by Merck Sharp and \& Dohme. The stock solutions of the compounds were prepared and stored in aliquots at $-80^{\circ} \mathrm{C}$ until use. No aliquot was refrozen once unfrozen. The MICs for IMI with and without REL (at a fixed concentration of $4 \mathrm{mg} / \mathrm{L}$ ) were determined by a standard broth microdilution method [7]. The MIC ranges used for IMI were 512 to $0.5 \mathrm{mg} / \mathrm{L}$ for resistant strains and $8 \mathrm{mg} / \mathrm{L}$ to $0.0625 \mathrm{mg} / \mathrm{L}$ for susceptible strains. Escherichia coli ATCC 25922 and Pseudomonas aeruginosa ATCC 27853 were included as quality controls in each MIC assay. MICs were measured using broth microdilution according to international recommendations [8].

\begin{tabular}{|c|c|c|c|}
\hline Table 1 & Cha & of the tested strains & \\
\hline Microorganisn & & Enzyme & $n$ \\
\hline Imipenem-sus & le Esch & & \\
\hline & & TEM & 8 \\
\hline & & СТXM 9 & 11 \\
\hline & & CTXM 15 & 14 \\
\hline & & SHV & 5 \\
\hline & & AmpC & 10 \\
\hline & & $A m p C+C T X M 9$ & 1 \\
\hline Imipenem-resi & Enterol & & \\
\hline Klebsiella p & noniae & & 30 \\
\hline & & KPC & 14 \\
\hline & & OXA 48 & 8 \\
\hline & & OXA $48+$ ESBL & 7 \\
\hline & & VIM & 1 \\
\hline Enterobact & acae & & 13 \\
\hline & & KPC & 5 \\
\hline & & OXA 48 & 4 \\
\hline & & VIM & 4 \\
\hline Serratia $m$ & & VIM & 2 \\
\hline Citrobacte & & VIM & 2 \\
\hline Klebsiella & & VIM & 1 \\
\hline Klebsiella c & & VIM & 1 \\
\hline Escherichio & & NDM & 1 \\
\hline Acinetobacter & nannii ( & & \\
\hline & & OXA23 & 10 \\
\hline & & OXA24+0XA58 & 1 \\
\hline & & OXA24 & 14 \\
\hline & & OXA51+ISAba1 & 11 \\
\hline & & OXA58 & 14 \\
\hline Pseudomonas & ginosal & & \\
\hline & & $0 p r D \downarrow+|-\uparrow A m p C+|-\uparrow M e x A B$ & 20 \\
\hline & & VIM & 19 \\
\hline & & KPC & 4 \\
\hline
\end{tabular}

\section{RESULTS}

As expected, all IMI-susceptible E. coli strains were also susceptible to IMI/REL. The $\mathrm{MIC}_{50}$ remained at $0.125 \mathrm{mg} / \mathrm{L}$ in both cases, and the $\mathrm{MIC}_{90}$ decreased 1 dilution, from $0.25 \mathrm{mg} / \mathrm{L}$ for IMI to 0.125 for IMI/REL.

In the Enterobacterales resistant to IMI due to the production of carbapenemases, the $\mathrm{MIC}_{50}$ and $\mathrm{MIC}_{90}$ decreased from 64/256 with IMI to 8/64 with IMI/REL. This high activity was principally detected among isolates with KPC enzymes. In these, the MIC values decreased at least 5 dilutions in up to $63.16 \%(12 / 19)$ of the strains. For the 12 Enterobacterales with class $B$ carbapenemases, there was no differences between the MIC with IMI and those with IMI/REL. In the same way, $19 P$. 


\begin{tabular}{|c|c|c|c|c|c|c|c|c|c|c|}
\hline Table 2 & \multicolumn{10}{|c|}{ MIC distribution of imipenem-resistant strains. } \\
\hline \multirow{2}{*}{\multicolumn{2}{|c|}{ Group of organism/ Enzyme }} & \multirow[t]{2}{*}{ N } & \multicolumn{4}{|c|}{$\begin{array}{c}\text { Imipenem MIC (mg/L) } \\
\mathrm{N}(\%)\end{array}$} & \multicolumn{4}{|c|}{$\begin{array}{l}\text { Imipenem/relebactam MIC (mg/L) } \\
\qquad \mathrm{N}(\%)\end{array}$} \\
\hline & & & $\leq 2$ & $\leq 4$ & $\leq 8$ & $\geq 16$ & $\leq 2$ & $\leq 4$ & $\leq 8$ & $\geq 16$ \\
\hline \multicolumn{11}{|c|}{ Enterobacterales $(n=49)$} \\
\hline KPC & & 19 & & & & $19(100)$ & $9(47.4)$ & $15(78.9)$ & $17(89.5)$ & $2(10.5)$ \\
\hline OXA $48+$ ESBL & & 7 & & & & $6(85.7)$ & $2(28.6)$ & $3(42.9)$ & $7(100)$ & \\
\hline OXA-48 & & 12 & & & & $12(100)$ & & & & $9(75)$ \\
\hline VIM / NDM & & $11 / 1$ & & & & $12(100)$ & & & & $12(100)$ \\
\hline Acinetobacter baun & annii $(n=50)$ & & $4(8)$ & $4(8)$ & $5(10)$ & $45(90)$ & $4(8)$ & $4(8)$ & $6(12)$ & $44(88)$ \\
\hline \multicolumn{11}{|c|}{ Pseudomonas aeruginosa $(\mathrm{n}=43)$} \\
\hline NO carbapenama & & 20 & $1(5)$ & $1(5)$ & $10(50)$ & $10(50)$ & $19(95)$ & $19(95)$ & $20(100)$ & \\
\hline VIM & & 19 & & $2(10.5)$ & $2(10.5)$ & $17(89.5)$ & $1(5.3)$ & $2(10.5)$ & $4(21,1)$ & \\
\hline KPC & & 4 & & & & $4(100)$ & $4(100)$ & & & \\
\hline
\end{tabular}

aeruginosa carrying VIM carbapenemase and all A. baumannii strains, showed no changes in the $\mathrm{MIC}_{50}$ and $\mathrm{MIC}_{90}(64-256$ $\mathrm{mg} / \mathrm{L}$, and 16 - $128 \mathrm{mg} / \mathrm{L}$ respectively). In P. aeruginosa isolates without carbapenemase (20/43), the MIC for IMI/REL was reduced between 1 to 5 dilutions. The group with carbapenemases obtained a reduction of 4 dilutions for the 4 KPC-carrying strains, obtaining $\mathrm{MIC} \leq 2$ in all strains (4/4). The distribution of MIC values is shown in Table 2 .

\section{DISCUSSION}

As expected, the addition of REL to IMI can improve the MIC of IMI in KPC carbapenemase-producing Enterobacterales, reaching up to 7 dilutions of difference [9-12]. For $P$. aeruginosa resistant to IMI due to reduced porin expression, associated or not with the overexpression of AmpC enzymes and efflux pumps, IMI/REL showed high activity. These results are in agreement with previous published studies [9- 11]. In our study, IMI/REL decreases MIC values 4 dilutions in $P$. aeruginosa strains with KPC enzymes, similarly to that observed in Enterobacterales.

Our results show that OXA-48 carrier strains were resistant to IMI/REL in almost 90\% of cases. The same results were obtained by other authors [12]. The difference observed in the MIC reduction between OXA-48-carrying Enterobacterales and those that also carry an ESBL suggest the presence of impermeability resistance mechanisms in the last ones. Other studies with strains resistant to IMI for the association of ESBL and/or AmpC with impermeability showed that IMI/REL reduced the MIC to IMI susceptibility values $[9,10,13]$. Finally, the Acinetobacter baumannii strains showed no improvement when adding REL to IMI, showing the lack of activity of REL on class $D$ enzymes characteristic of $A$. baumannii [10].
This analysis may be subject to some limitations. Due to the low stability of imipenem, the concentration of active drug in the titrated substance used in the experiments could be less than the expected. This fact could justify an increase in the MICs obtained, especially in the case of those carriers of carbapenemases of the KPC family compared with previous published data [9- 3]. In addition, the selection of the strains was based on the mechanisms of resistance instead of frequency of appearance in clinical samples being not representative of the local susceptibility of these 3 groups.

IMI/REL shows high activity against KPC carrier strains. This, together with its effective inhibition of other high-dispersion broad-spectrum beta-lactamases such as ESBL and AmpC, as well as the combination's low susceptibility to active efflux pumps, makes this combination an alternative treatment for infections caused by KPC carbapenemase-carrying Enterobacterales with or without other associated mechanisms of beta-lactam resistance. The study conducted by Haidar et al. [14] showed that IMI/REL also maintains its activity in strains with KPC-2 and KPC-3 mutations, associated with resistance to another new combination: ceftazidime/avibactam. Similarly, IMI/ REL appears to be a good candidate for those medical centers that, in addition to the above-mentioned problem with KPC carbapenemases, have multidrug-resistant $P$. aeruginosa that do not carry VIM carbapenemases.

\section{FUNDING}

None to declare

\section{CONFLICT OF INTEREST}

Authors declare no conflict of interest 


\section{ACKNOWLEDGMENTS}

The investigators would like to thank Merck Sharp Down (MSD) Laboratories for providing the tested substance of Imipenem and Relebactam necessary to carry out this study.

\section{REFERENCES}

1. European Centre for Disease Prevention and Control. Carbapenem-resistant Enterobacteriaceae, second update - 26 September 2019. ECDC: Stockholm; 2019.

2. Prioritization of pathogens to guide discovery, research and development of new antibiotics for drug-resistant bacterial infections, including tuberculosis. Geneva: World Health Organization; 2017(WHO/EMP/IAU/2017.12).

3. Lucasti C, Vasile L, Sandesc D, Venskutonis D, McLeroth P, Lala M, Rizk ML, Brown ML, Losada MC, Pedley A, Kartsonis NA, Paschke A. 2016. Phase 2, dose-ranging study of relebactam with imipenem-cilastatin in subjects with complicated intra-abdominal infection. Antimicrob Agents Chemother 60: 6234-6243. doi:10.1128/ AAC.00633-16.

4. Lob SH, Hackel MA, Kazmierczak KM, Hoban DJ, Young K, Motyl MR, Karlowsky JA, Sahm DF. 2017. In vitro activity of imipenem-relebactam against gram-negative bacilli isolated from patients with lower respiratory tract infections in the United States in 2015: results from the SMART global surveillance program. Diagn Microbiol Infect Dis 88:171-176. doi:10.1016/j.diagmicrobio.2017.02.018.

5. López-Diaz MD, Culebras E, Rodríguez-Avial I, Rios E, Viñuela-Prieto JM, Picazo JJ, Rodríguez-Avial C. Plazomicin Activity against 346 Extended-Spectrum- $\beta$-Lactamase/AmpC-Producing Escherichia coli Urinary Isolates in Relation to Aminoglycoside-Modifying Enzymes. Antimicrob Agents Chemother. 2017; 61(2). pii: e02454-16.

6. Rodríguez-Avial I, Pena I, Picazo JJ, Rodríguez-Avial C, Culebras E. In vitro activity of the next-generation aminoglycoside plazomicin alone and in combination with colistin, meropenem, fosfomycin or tigecycline against carbapenemase-producing Enterobacteriaceae strains. Int J Antimicrob Agents. 2015; 46: 616-21.

7. Methods for Dilution Antimicrobial Susceptibility Tests for Bacteria That Grow Aerobically. 11th ed. CLSI standard M07. Wayne, PA: Clinical and Laboratory Standards Institute; 2018.

8. International Organization for Standards. Susceptibility testing of infectious agents and evaluation of performance of antimicrobial susceptibility testing devices. Part 1: Broth micro-dilution reference method for testing the in vitro activity of antimicrobial agents against rapidly growing anaerobic bacteria involved in infectious diseases. ISO 20776-1:2019. Geneva: International Organization for Standards; 2019

9. Livermore DM, Warner M, Mushtaq S. 2013. Activity of MK-7655 combined with imipenem against Enterobacteriaceae and Pseudomonas aeruginosa. J Antimicrob Chemother 68:2286 -2290. doi:10.1093/jac/dkt178.

10. Lapuebla A, Abdallah M, Olafisoye $\mathrm{O}$, Cortes $\mathrm{C}$, Urban C, Landman D, Quale J. 2015. Activity of imipenem with relebactam against Gram-negative pathogens from New York City. Antimicrob Agents
Chemother 59: 5029-5031. doi:10.1128/AAC.00830-15.

11. Young K, Raghoobar SL, Hairston NN, Painter RE, Racine F, Dorso KL, Park Y-W, Ogawa AM, Wisniewski D, Hermes J, Blizzard TA, Hammond ML, Motyl MR. 2010. In vitro activity of the class A and C $\beta$-lactamase inhibitor MK-7655. ICAAC 2010, Boston, MA, poster F1-2139.

12. Canver MC, Satlin MJ, Westblade LF, Kreiswirth BN, Chen L, Robertson A, Fauntleroy K, La Spina M, Callan K, Jenkins SG. 2019. Activity of Imipenem-Relebactam and comparator agents against genetically characterized isolates of carbapenem-resistant-Enterobacteriaceae. Antimicrob Agents Chemother 63: e00672-19. doi:10.1128/AAC.00672-19

13. Lob SH, Hackel MA, Kazmierczak KM, Young K, Motyl MR, Karlowsky JA, Sahm DF. 2017. In vitro activity of imipenem-relebactam against Gram-negative ESKAPE pathogens isolated by clinical laboratories in the United States in 2015 (results from the SMART global surveillance program). Antimicrob Agents Chemother 61: e02209-16. doi:10.1128/AAC.02209-16.

14. Haidar G, Clancy CJ, Chen L, Samanta P, Shields RK, Kreiswirth BN, Nguyen MH. 2017. Identifying spectra of activity and therapeutic niches for ceftazidime-avibactam and imipenem-relebactam against carbapenem-resistant Enterobacteriaceae. Antimicrob Agents Chemother 61: e00642-17. doi:10 .1128/AAC.00642-17. 